\title{
Acute Myelomonocytic Leukemia without Abnormal Eosinophils
}

National Cancer Institute

\section{Source}

National Cancer Institute. Acute Myelomonocytic Leukemia without Abnormal

Eosinophils. NCl Thesaurus. Code C42779.

Acute myelomonocytic leukemia without an abnormal eosinophilic component in the bone marrow. 